\title{
Comparison of Double Sleeve Lobectomy by Uniportal Video-Assisted Thoracic Surgery (VATS) and Thoracotomy for NSCLC Treatment
}

This article was published in the following Dove Press journal: Cancer Management and Research

\author{
Liang $\mathrm{Wu}^{\prime}$ \\ Hao Wang ${ }^{2}$ \\ Haomin Cai \\ Jiang Fan' \\ Gening Jiang' \\ Yayi $\mathrm{He}\left(\mathbb{D}^{3}\right.$ \\ Lei Jiang' \\ 'Department of Surgery, Shanghai \\ Pulmonary Hospital, Tongji University \\ Medical School Cancer Institute, Tongji \\ University School of Medicine, Shanghai \\ 200433, People's Republic of China; \\ ${ }^{2}$ Medical School, Tongji University, \\ Shanghai 200433, People's Republic of \\ China; ${ }^{3}$ Department of Medical \\ Oncology, Shanghai Pulmonary Hospital, \\ Tongji University Medical School Cancer \\ Institute, Tongji University School of \\ Medicine, Shanghai 200433, People's \\ Republic of China
}

Correspondence: Yayi He; Lei Jiang

Tel/fax +862165II 5006

Email 225060I@qq.com;

leijiang2356@yahoo.com
Background: With the development of the surgical technique and experience of surgeons, uniportal VATS has been used in double sleeve lobectomy to treat non-small cell lung cancer (NSCLC). This retrospective study aims to evaluate the efficacy and safety of uniportal VATS in NSCLC treatment.

Methods: We reviewed 42 NSCLC patients who underwent double sleeve lobectomy in Shanghai Pulmonary Hospital from June 2015 to November 2017. 21 patients received double sleeve lobectomy through uniportal VATS and 21 through conventional thoracotomy with large incision.

Results: The characteristics of patients were similar between the two groups. The operation time was longer in the uniportal VATS group $(p=0.021)$ and the drainage on postoperation day 1 was significantly less in the uniportal VATS group $(p=0.004)$. Patients reported a lower postoperative pain level in the uniportal VATS group than in the thoracotomy group $(p=0.002)$. No statistically significant difference showed in other aspects.

Conclusion: Uniportal VATS double sleeve lobectomy for NSCLC treatment is safe and effective. Lower postoperative pain level was found in the uniportal VATS group. Its complication rate and postoperation survival were similar to the conventional thoracotomy approach with large incision. But a large randomized clinical trial is still necessary for further investigation.

Keywords: sleeve lobectomy, uniportal video-assisted thoracic surgery, VATS, thoracotomy

\section{Introduction}

Lung cancer is one of the commonest cancers with high mortality in the world. ${ }^{1}$ Nowadays, a variety of methods have been applied to lung cancer treatment, such as operation, ${ }^{2,3}$ chemotherapy, target therapy ${ }^{4}$ and immunotherapy. ${ }^{5}$ But complete resection is still a critical treatment with curative intent for early stage lung cancer. For central lung cancer, pneumonectomy was a common procedure in the past. In recent years there were several studies finding that sleeve lobectomy could be an alternative to pneumonectomy. ${ }^{6-8}$ With the development of the technique and surgeons' experience, video-assisted thoracic surgery (VATS) sleeve lobectomy and even VATS double sleeve lobectomy have been reported..$^{9-11}$ Thus, it is essential to investigate whether VATS double sleeve lobectomy, especially uniportal VATS, can provide a similar or even better outcome compared to the thoracotomy method.

We did a retrospective study to explore the safety and efficacy of uniportal VATS double sleeve lobectomy for non-small cell lung cancer (NSCLC) and compare the outcome with the operation performed through thoracotomy. 


\section{Methods}

\section{Patients}

We reviewed 42 patients who received double sleeve lobectomy through conventional thoracotomy or uniportal VATS with curative intent for lung cancer from June 2015 to November 2017 in our hospital. Bronchoscopy was routinely performed before surgery in order to make sure of the possibility for bronchial sleeve resection. Preoperative classification was determined after an enhanced chest CT scan, ultrasound bronchoscopy, brain MRI and bone imaging of the patients. Postoperative pathological classification was according to the IASLC Eighth Edition of the TNM Classification for Lung Cancer. $^{12}$ The study was approved by Shanghai Pulmonary Hospital, Tongji University, in accordance with the guidelines of the Helsinki Declaration of 1975, revised in 1983. All participants provided written informed consent.

\section{Procedure}

All patients underwent standard general anesthesia and double-lumen endotracheal intubation. The patients' position was lateral decubitus. For patients who had uniportal VATS, we made a $4 \mathrm{~cm}$ incision at the anterior axillary line in the fourth intercostal space to insert the surgical instrument. The tourniquet technique ${ }^{13}$ was applied to occlude the proximal and distal pulmonary artery. Scissors were used to divide and trim the bronchus and the artery. The corresponding lobe was resected simultaneously. Hilar and mediastinal lymph node resection was conducted during the operation. The resected bronchial stump was sent for frozen pathological examination to identify whether the margin was free of cancer. If it was negative, the bronchus anastomosis would be performed. We performed a suture with 3-0 prolene for cartilaginous and membranous portions. When the bronchial anastomosis was completed, the artery was anastomosed continuously with 5-0 prolene. The resected lobe was removed through the port. Saline was used to wash the chest and the lung was inflated to identify any potential air leak. A $28 \mathrm{Fr}$ chest tube was put into the chest.

For the thoracotomy group, we performed a conventional posterolateral thoracotomy large incision of about $20 \mathrm{~cm}$ at the fourth or fifth intercostal space and the muscle was incised. The involved bronchus was resected and sent for frozen pathological examination. Related lobe and mediastinum lymph nodes were also removed. We performed bronchus anastomosis with 3-0 prolene for continuous suturing or 4-0 vicryl for interrupted suturing. Pulmonary arterial anastomosis was also performed by continuous suturing with 5-0 prolene. Saline was used to wash the chest and the lung was inflated to identify any potential air leak. A 28 Fr chest tube was put into the chest.

After operation, patients would be sent back to the wards after they were stable in the intensive care unit. We used the numeric rating scale (NRS) to measure the pain level of the patients, in which 0 represented "no pain" and 10 represented "the worst pain". The highest score was used to represent the postoperative pain level. Postoperative complications were defined as symptoms that occurred within 30 days after surgery.

Follow-up was conducted every 3 months, and the patients underwent the CT scan or chest radiography. The follow-up was to June 2018.

\section{Statistical Analysis}

Statistical analysis was obtained by SPSS 22.0 (SPSS Inc., Chicago, IL, USA). Measurement data shown as the mean (SD) were analyzed by $t$-test, or shown as the median $\left(\mathrm{P}_{25}\right.$ $-\mathrm{P}_{75}$ ) were analyzed by the Wilcoxon rank sum test. Enumeration data expressed as the number (proportion) were analyzed by the chi-square test. For survival analysis, we used the Kaplan-Meier method and compared by the log rank test. The Cox model was applied for multivariable analysis in survival data and the result would be shown as the hazard ratio (HR) and corresponding 95\% confidence interval $(95 \% \mathrm{CI})$. Statistical significance was considered as $p$ value less than 0.05 .

\section{Results}

Of the 42 patients, 21 had double sleeve lobectomy through thoracotomy and 21 through uniportal VATS. Characteristics of patients in the two groups are shown in Table 1. The proportion of patients with a smoking history showed no statistical significance. There were two patients in both groups having neoadjuvant chemotherapy before operation and no patient had a history of thoracic surgery. No significant difference between the two groups was found in preoperative pulmonary function and arterial blood gas analysis. Tumor characteristics of the patients were also collected and are shown in Table 1. The diameter of the tumor showed no statistical difference between the two groups. Either the uniportal VATS group or the thoracotomy group had more patients with 
Table I Characteristics of Patients

\begin{tabular}{|c|c|c|c|}
\hline & $\begin{array}{l}\text { Uniportal VATS } \\
(n=21)\end{array}$ & $\begin{array}{l}\text { Thoracotomy } \\
(n=21)\end{array}$ & $p$ Value \\
\hline Age (years) & $62(59-68)$ & $61(56-64)$ & 0.134 \\
\hline \multicolumn{3}{|l|}{ Sex } & 1.000 \\
\hline Male & 19 (90.5\%) & 19 (90.5\%) & \\
\hline Female & $2(9.5 \%)$ & $2(9.5 \%)$ & \\
\hline \multicolumn{3}{|l|}{ Smoking } & 0.057 \\
\hline Yes & $16(76.2 \%)$ & $10(47.6 \%)$ & \\
\hline No & $5(23.8 \%)$ & II (52.4\%) & \\
\hline BMI $\left(\mathrm{kg} / \mathrm{m}^{2}\right)$ & $22.75(3.09)$ & $22.68(2.38)$ & 0.903 \\
\hline Albumin $(g / L)$ & $37.71(2.61)$ & $40.14(3.84)$ & $0.021 *$ \\
\hline $\mathrm{Hb}(\mathrm{g} / \mathrm{L})$ & $127.43(14.37)$ & $133.19(|2.7|)$ & 0.176 \\
\hline FEVI (L) & $2.20(0.5 I)$ & $2.52(0.5 I)$ & 0.057 \\
\hline $\mathrm{PaCO}_{2}(\mathrm{mmHg})$ & $39.11(2.18)$ & $39.14(3.05)$ & 0.968 \\
\hline $\mathrm{PaO}_{2}(\mathrm{mmHg})$ & $87.38(8.22)$ & 87.95 (12.18) & 0.860 \\
\hline $\mathrm{SaO}_{2}(\%)$ & $97.12(0.74)$ & $97.20(1.02)$ & 0.797 \\
\hline Diameter $(\mathrm{cm})$ & $3.73(1.38)$ & $4.18(2.92)$ & 0.525 \\
\hline \multicolumn{3}{|l|}{ Lesion } & 0.694 \\
\hline Left upper lobe & $18(85.7 \%)$ & $16(76.2 \%)$ & \\
\hline Right upper lobe & $3(14.3 \%)$ & $5(23.8 \%)$ & \\
\hline \multicolumn{3}{|l|}{ Pathology } & 0.798 \\
\hline $\begin{array}{l}\text { Squamous cell } \\
\text { carcinoma }\end{array}$ & $14(66.7 \%)$ & $16(76.2 \%)$ & \\
\hline Adenocarcinoma & 4 (19.0\%) & 4 (19.0\%) & \\
\hline $\begin{array}{l}\text { Large cell } \\
\text { carcinoma }\end{array}$ & $2(9.5 \%)$ & $0(0.0 \%)$ & \\
\hline $\begin{array}{c}\text { Sarcoid } \\
\text { carcinoma }\end{array}$ & I (4.8\%) & I (4.8\%) & \\
\hline \multicolumn{3}{|l|}{ TNM stage } & 0.642 \\
\hline la & I (4.8\%) & I (4.8\%) & \\
\hline $\mathrm{Ib}$ & 7 (33.3\%) & $6(28.6 \%)$ & \\
\hline $2 a$ & I (4.8\%) & $0(0.0 \%)$ & \\
\hline $2 b$ & $3(14.3 \%)$ & $6(28.6 \%)$ & \\
\hline $3 a$ & 7 (33.3\%) & $8(38.1 \%)$ & \\
\hline $3 b$ & $2(9.5 \%)$ & $0(0.0 \%)$ & \\
\hline
\end{tabular}

Notes: Data are presented as mean (SD), median $\left(\mathrm{P}_{25}-\mathrm{P}_{75}\right)$ or $\mathrm{n}(\%)$. ${ }^{*} p<0.05$. Abbreviations: VATS, video-assisted thoracic surgery; BMI, body mass index; $\mathrm{Hb}$, hemoglobin; FEVI, forced expiratory volume in I second.

lesions located at the left upper lobe. But the tumor location between the two groups showed no statistical difference. The distribution of histologic types and postoperative pathological staging between the two groups had no significant difference. The postoperative nodal stage is extracted in Table 2 separately.

All patients had the angioplastic procedure of vascular sleeve resection. There was no patient in the uniportal VATS group converting to thoracotomy during operation. The
Table 2 Nodal Status of Patients

\begin{tabular}{|l|l|l|l|}
\hline & $\begin{array}{l}\text { Uniportal VATS } \\
(\mathbf{n = 2 1})\end{array}$ & $\begin{array}{l}\text { Thoracotomy } \\
(\mathbf{n = 2} \text { I) }\end{array}$ & $p$ Value \\
\hline N0 & $10(47.6 \%)$ & $8(38.1 \%)$ & 0.231 \\
NI & $2(9.5 \%)$ & $7(33.3 \%)$ & \\
N2 & $9(42.9 \%)$ & $6(28.6 \%)$ & \\
\hline
\end{tabular}

median operation time was $4 \mathrm{~h}$ in uniportal VATS and 3 $\mathrm{h}$ in thoracotomy, and statistical difference was found between the two groups ( $p=0.021)$. No significant difference in perioperative blood loss between the two operation methods was found in our study (Table 3 ). The number of lymph node stations and lymph nodes harvested during operation are listed in Table 3 and showed no statistical difference. No positive margin was reported in both groups. Drainage on postoperation day 1 was significantly more in thoracotomy than in uniportal VATS ( $p=0.004)$. However, the length of postoperative hospital stay had no statistical difference. Also, no patients in both groups were readmitted because of operation-related problems after they were discharged. The complications reported in our study were fever, subcutaneous emphysema, infection and arrhythmia. No lifethreatening complications were reported. Three patients in uniportal VATS and one patient in thoracotomy suffered postoperative complications but the difference was not statistically significant. There was no operation-related death reported. Postoperative pain data were also collected and analyzed (Figure 1). Ppostoperative pain scores were significantly higher in the thoracotomy group than in the uniportal VATS group $(p=0.002)$.

All patients in the thoracotomy group completed the follow-up, but three patients $(14.3 \%)$ in the uniportal VATS group were lost. The estimated median disease free survival in uniportal VATS was 36 months in our study. In univariate analysis, no statistically significant difference was detected in disease free survival (Figure 2) and overall survival (Figure 3). No variable showed a statistically positive or negative effect on DFS of the patients (Table 4).

\section{Discussion}

Since sleeve lobectomy was performed for bronchogenic carcinoma in $1954,{ }^{8}$ it had been considered as an alternative method for pneumonectomy. Sleeve lobectomy could maximally remove the tumor and maximally preserve normal lung tissue. ${ }^{7}$ Several studies had demonstrated that sleeve lobectomy might provide a better outcome than pneumonectomy. ${ }^{6,14-16}$ VATS had shown 
Table 3 Operation Data

\begin{tabular}{|c|c|c|c|}
\hline & Uniportal VATS $(n=2 I)$ & Thoracotomy $(n=21)$ & $p$ Value \\
\hline Operation time $(\mathrm{h})$ & $4(3-5)$ & $3(2-4)$ & $0.021 *$ \\
\hline Operative blood loss ( $\mathrm{mL})$ & $200(100-200)$ & $100(100-400)$ & 0.658 \\
\hline Lymph node station & $5(5-6)$ & $6(5-7)$ & 0.111 \\
\hline Lymph node number & $9(8-13)$ & $10(7-14)$ & 0.870 \\
\hline Positive lymph nodes & I (0-4) & I (0-2) & 0.712 \\
\hline Drainage on PODI (mL) & $250(150-300)$ & $400(300-450)$ & $0.004^{*}$ \\
\hline Postoperative hospital stay (days) & $6(4-7)$ & $6(5-8)$ & 0.380 \\
\hline Complications & $3(14.3 \%)$ & I (4.8\%) & 0.599 \\
\hline Fever & $2(9.5 \%)$ & $0(0.0 \%)$ & 0.469 \\
\hline Subcutaneous emphysema and pulmonary infection & I (4.8\%) & $0(0.0 \%)$ & 1.000 \\
\hline Cardiac arrhythmia & $0(0.0 \%)$ & I (4.8\%) & 1.000 \\
\hline
\end{tabular}

Notes: Data are presented as median $\left(\mathrm{P}_{25}-\mathrm{P}_{75}\right)$ or $\mathrm{n}(\%)$. ${ }^{*} p<0.05$.

Abbreviation: PODI, postoperation day $\mathrm{I}$.

its similar, even better, outcome when compared to thoracotomy. ${ }^{17-21}$ VATS had a lower level of acute phase reaction and slighter suppression of the patient immune reaction. $^{22}$ Recently, sleeve lobectomy with or without angioplastic procedure has been reported to be performed by VATS, ${ }^{9,23-25}$ even uniportal VATS. ${ }^{10,11,26,27}$

In our study, the operation time was longer in uniportal VATS. Considering that uniportal VATS double sleeve lobectomy is a more complicated procedure, the requirement of longer time should be acceptable. Operative blood loss ranged from study to study. Mahtabifard et al reported that median operative blood loss was $250 \mathrm{~mL} .^{28} \mathrm{Xu}$ et al showed the average operative blood loss was $207 \pm 96 \mathrm{~mL}$. ${ }^{29}$ Another study in a Chinese population reported that as 390 $\pm 206 \mathrm{~mL}^{30}$ A multicenter study showed that the median operative blood loss was $224 \mathrm{~mL}^{25}$ We found the median operative blood loss was $200 \mathrm{~mL}$ and it showed no significant difference when compared to thoracotomy. This consequence corresponded to a previous study. ${ }^{31}$ This result indicated that the VATS approach might have smaller damage to the lungs of the patients.

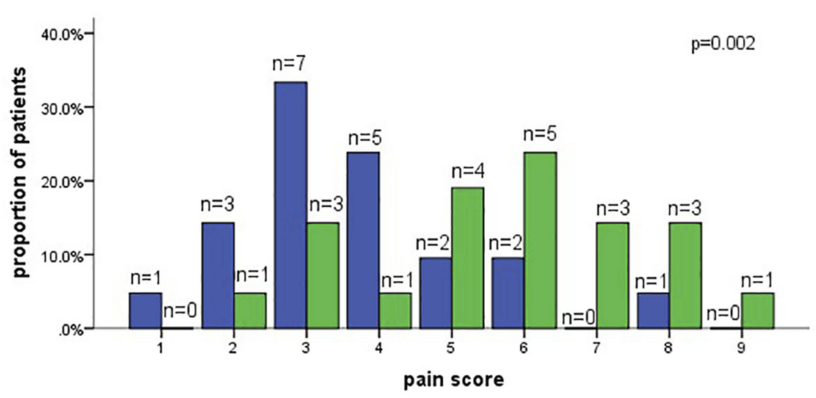

Figure I Patients' reported pain scores after surgery.
Before operation, patients always had some days for diagnosis and preoperative examination. Thus, compared to total hospitalization, the postoperative hospital stay might be a more sensitive variable to show safety of the operation indirectly. So, we collected postoperative hospital stay as our data for analysis. It showed no statistical difference between the two groups. But one study found that the VATS approach had an obviously shorter postoperative hospital stay. ${ }^{31}$ In another study, the median postoperative hospital stay was 10 days, ${ }^{29}$ which was similar to that found by Huang et al. ${ }^{25}$

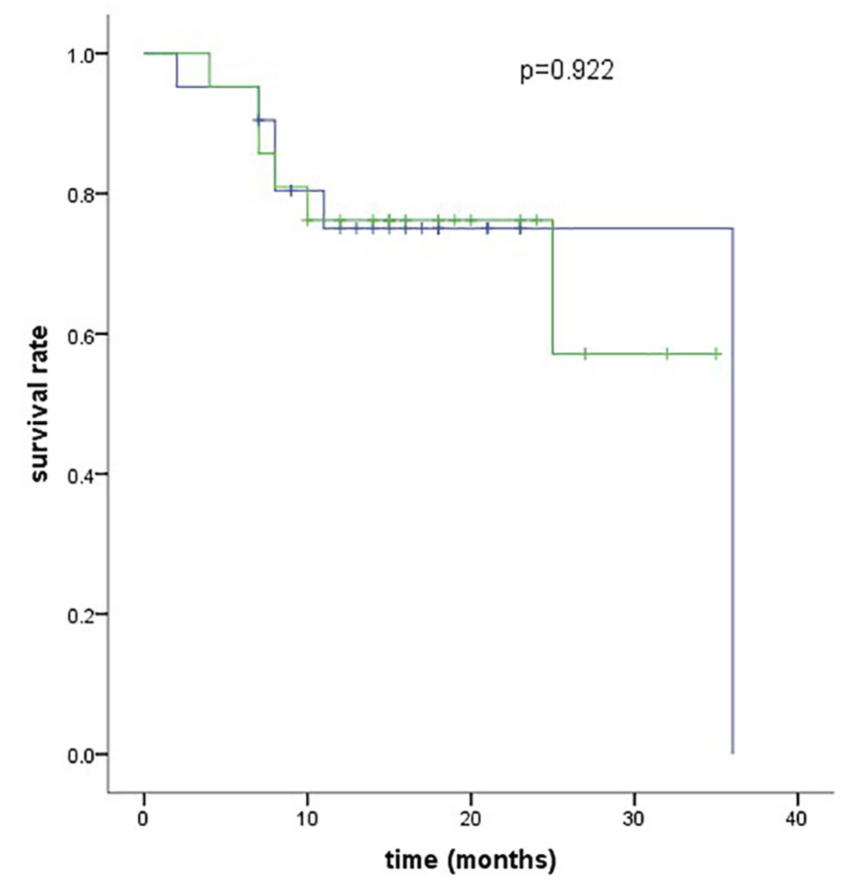

Figure 2 Kaplan-Meier curve for disease free survival. 


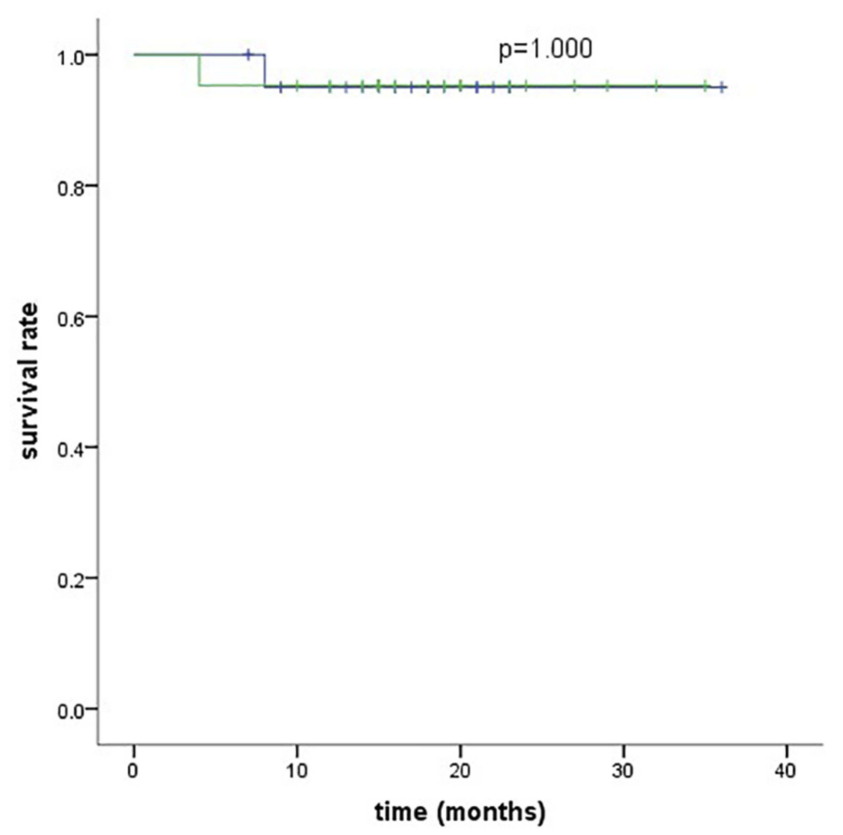

Figure 3 Kaplan-Meier curve for overall survival.

Because of safety, complete resection and technological issues, conversion to thoracotomy might be required. Hilar lymphadenopathy and bleeding were the commonest reason for conversion followed by fusion of fissure and lymph node metastasis. ${ }^{32}$ We found that the total lymph node station and total lymph nodes which were resected in the uniportal VATS operation were similar to those in thoracotomy. This result was also confirmed by Zhou et al. ${ }^{31}$ The result might suggest that uniportal VATS was effective for patients who needed lymphadenectomy.

Pneumonia, pulmonary embolism, atelectasis, prolonged air leak, empyema, etc. might occur as major complications after sleeve lobectomy. ${ }^{8}$ Some of them are severe and lifethreatening, such as bronchovascular fistula, bronchopleural fistula and bronchial stenosis. According to our study, only three patients in the uniportal VATS group had postoperative complications and no patient suffered from those severe complications or died within 30 days after operation. Compared to thoracotomy, uniportal VATS had relatively more complications but no significant difference occurred. Zhou et al described that only one patient of 10 in the VATS group had atrial fibrillation as a complication. ${ }^{31}$ Huang et al reported that only one patient who had had six cycles of neoadjuvant chemotherapy was diagnosed with pneumonia after operation. ${ }^{25}$ Some studies reported that major postoperative complications could not occur. ${ }^{29,30}$ But Mahtabifard et al reported that two patients went through severe complications after surgery. ${ }^{28}$ This discrepancy may
Table 4 Multivariable Analysis for Disease Free Survival (DFS)

\begin{tabular}{|c|c|c|c|}
\hline Variable & HR & $95 \% \mathrm{Cl}$ & $p$ Value \\
\hline \multicolumn{4}{|l|}{ Approach } \\
\hline Thoracotomy & Reference & - & - \\
\hline Uniportal VATS & 0.573 & $0.126-2.608$ & 0.471 \\
\hline \multicolumn{4}{|l|}{ Sex } \\
\hline Male & Reference & - & - \\
\hline Female & 6.734 & $0.177-256.310$ & 0.304 \\
\hline \multicolumn{4}{|l|}{ Age (years) } \\
\hline$<62$ & Reference & - & - \\
\hline$\geq 62$ & 1.017 & $0.286-3.621$ & 0.979 \\
\hline \multicolumn{4}{|l|}{ Smoking } \\
\hline Never & Reference & - & - \\
\hline Current & 1.462 & $0.149-|4.32|$ & 0.744 \\
\hline \multicolumn{4}{|l|}{ Location of the lesion } \\
\hline LUL & Reference & - & - \\
\hline RUL & 1.125 & $0.143-8.849$ & 0.911 \\
\hline \multicolumn{4}{|l|}{ Diameter $(\mathrm{cm})$} \\
\hline$<4$ & Reference & - & - \\
\hline$\geq 4$ & 6.809 & $0.520-89.090$ & 0.144 \\
\hline \multicolumn{4}{|c|}{ Preoperative chemotherapy } \\
\hline Have & Reference & - & - \\
\hline Never & 4.16 & $0.594-38.708$ & 0.159 \\
\hline \multicolumn{4}{|l|}{ Pathology } \\
\hline $\begin{array}{l}\text { Squamous cell } \\
\text { carcinoma }\end{array}$ & & - & - \\
\hline Adenocarcinoma & 2.546 & $0.715-9.068$ & 0.149 \\
\hline Large cell carcinoma & 1.88 & $0.213-16.621$ & 0.57 \\
\hline Sarcoid carcinoma & 0 & - & 0.988 \\
\hline \multicolumn{4}{|l|}{ TNM stage } \\
\hline I & Reference & - & - \\
\hline II & 5.814 & $0.646-52.343$ & 0.116 \\
\hline III & 6.136 & $0.726-51.135$ & 0.094 \\
\hline \multicolumn{4}{|l|}{$N$ stage } \\
\hline No & Reference & - & - \\
\hline $\mathrm{NI}$ & 2.836 & $0.47 I-17.080$ & 0.255 \\
\hline N2 & 4.594 & $0.925-22.826$ & 0.062 \\
\hline
\end{tabular}

relate to individual difference of the patients and surgeons' experience, not just the VATS approach itself.

Intense postoperative pain will make patients debilitated and have a negative impact on patients' recovery. Thus, postoperative pain should also be considered as an 
important factor when evaluating an operation method. Present studies have confirmed less postoperative pain in multiportal VATS. A study containing 3900 patients found that patients who underwent VATS were less likely to use opioids after surgery. ${ }^{33}$ A randomized trial found that more patients reported moderate-to-severe pain $(\mathrm{NRS} \geq 3$ ) in thoracotomy than VATS. Also, patients in VATS tended to have a significantly shorter duration of epidural analgesia after the surgery. Meanwhile, during the whole followup, the EuroQol 5 Dimensions (EQ5D) scores reported by patients were significantly better in the VATS group. ${ }^{18}$ In our study, we obtained the result that the pain scores were significantly lower in patients who had double sleeve lobectomy through uniportal VATS. This corresponded to the previous studies. Theoretically, uniportal VATS with only one port can be considered as a less invasive approach than multiportal VATS. In general opinion, it should be a less painful approach. But in a present study, McElnay et al found the dosage of morphine used in the first $24 \mathrm{~h}$ after operation and patients reported pain scores were comparable between the uniportal and multiportal groups. $^{34}$ This suggests further studies are indispensable to investigate whether uniportal VATS has a different pain level.

Survival is another important aspect to evaluate the efficacy of operations. Several studies have reported longterm survival data for thoracotomy sleeve lobectomy. Chunwei et al reported that the overall survival rate at 5 and 10 years was $48.9 \%$ and $38.8 \%$ respectively. ${ }^{35}$ Takeda et al showed the 5-year overall survival rate was $54.3 \%$, while the rate in the work of Ludwig et al was just $39 \%{ }^{14,16}$ A meta-analysis reported the overall 5-year survival rate was $50.3 \%$ and the median overall survival was 60 months. ${ }^{6}$ Long-term outcome of VATS sleeve lobectomy was limited. It was reported in a retrospective study that the overall 1-, 2-, 3-, and 4-year survival rate was $100 \%, 89 \%, 63 \%$, and $40 \%$ respectively. Also, they suggested the overall median survival was similar between VATS and the thoracotomy approach. ${ }^{31}$ According to our study, the survival between uniportal VATS and thoracotomy showed no statistical difference. This indicated that we could use the less invasive method to achieve a similar goal of survival. For prognosis, nodal status is also considered as a reliable factor. The survival rate varied between different pathological nodal stages. ${ }^{35}$ However, it did not occur in our present study. This might be due to our relatively small sample size and short follow-up.
It had been reported that bronchoplastic surgery was still a safety operation method for patients who had had induction therapy. ${ }^{36}$ However, Takeda et al showed that three patients who received induction therapy before sleeve lobectomy finally died because of empyema or respiratory failure. ${ }^{14}$ Huang et al reported that a patient receiving six cycles of neoadjuvant chemotherapy suffered pneumonia after thoracoscopic double sleeve lobectomy. ${ }^{25}$ In our study, severe complications had not been found. But one patient who had had chemotherapy before surgery had a fever after surgery. This might suggest that uniportal VATS double sleeve lobectomy could be safe to apply for patients with neoadjuvant chemotherapy, but these patients would need more attention after surgery.

Our study compares double sleeve lobectomy through uniportal VATS and thoracotomy which is relatively limited currently. But some limitations exist in our study. First, the number of samples in our study is small. Second, this is a retrospective study, which means its non-randomization and unknown confounding variables might affect the study result.

\section{Conclusion}

We can preliminarily infer that uniportal VATS double sleeve lobectomy is a safe and effective operation method for NSCLC patients. This operative technique shows a comparable occurrence of complications and survival as the conventional thoracotomy approach with large incision does. At the same time, it brings patients a lower level of postoperative pain. But considering the limitations that exist in our study, large randomized trials should be conducted in the future.

\section{Acknowledgments}

This study was supported in part by grants from National Natural Science Foundation of China (81802255), Shanghai Pujiang Program (17PJD036), Shanghai Municipal Commission of Health and Family Planning Program (20174Y0131), National Key Research \& Development Project (2016YFC0902300), Major Disease Clinical Skills Enhancement Program of Three Year Action Plan for Promoting Clinical Skills and Clinical Innovation in Municipal Hospitals, Shanghai Shen Kang Hospital Development Center Clinical Research Plan of SHDC (16CR1001A), and the fundamental research funds for the central universities. Liang $\mathrm{Wu}$, Hao Wang, and Haomin Cai are co-first authors for this study. 


\section{Disclosure}

The authors report no conflicts of interest in this work.

\section{References}

1. Torre LA, Bray F, Siegel RL, Ferlay J, Lortet-Tieulent J, Jemal A. Global cancer statistics, 2012. CA Cancer J Clin. 2015;65:87-108. doi: $10.3322 /$ caac. 21262

2. Lang-Lazdunski L. Surgery for nonsmall cell lung cancer. Eur Respir Rev. 2013;22:382-404. doi:10.1183/09059180.00003913

3. Gonzalez-Rivas D, Yang Y, Ng C. Advances in uniportal video-assisted thoracoscopic surgery: pushing the envelope. Thorac Surg Clin. 2016;26:187-201. doi:10.1016/j.thorsurg.2015.12.007

4. Wakelee H, Kelly K, Edelman MJ. 50 Years of progress in the systemic therapy of non-small cell lung cancer. Am Soc Clin Oncol Educ Book Am Soc Clin Oncol Annu Meeting. 2014;177-189. doi:10.14694/EdBook_AM.2014.34.177

5. Taube JM, Klein A, Brahmer JR, et al. Association of PD-1, PD-1 ligands, and other features of the tumor immune microenvironment with response to anti-PD-1 therapy. Clin Cancer Res. 2014;20:5064-5074. doi:10.1158/1078-0432.CCR-13-3271

6. Ma Z, Dong A, Fan J, Cheng H. Does sleeve lobectomy concomitant with or without pulmonary artery reconstruction (double sleeve) have favorable results for non-small cell lung cancer compared with pneumonectomy? A meta-analysis. Eur $J$ Cardio-Thoracic Surg. 2007;32:20-28. doi:10.1016/j.ejcts.2007.03.018

7. Schirren J, Bolukbas S, Bergmann T, Fisseler-Eckhoff A, Trainer S, Beqiri S. Prospective study on perioperative risks and functional results in bronchial and bronchovascular sleeve resections. Thorac Cardiovasc Surg. 2009;57:35-41. doi:10.1055/s-2008-1038985

8. Fabre D, Fadel E, Chataigner O, Dartevelle PG, Mussot S, Yildizeli B. Morbidity, mortality, and long-term survival after sleeve lobectomy for non-small cell lung cancer 2 . Eur J Cardio-Thoracic Surg. 2007;31:95-102. doi:10.1016/j.ejcts.2006.10.031

9. Li Y, Wang J. Video-assisted thoracoscopic surgery sleeve lobectomy with bronchoplasty: an improved operative technique. Eur J CardioThoracic Surg. 2013;44:1108-1112. doi:10.1093/ejcts/ezt199

10. Gonzalez-Rivas D, Delgado M, Fieira E, Pato O. Left lower sleeve lobectomy by uniportal video-assisted thoracoscopic approach. Interact Cardiovasc Thorac Surg. 2014;18:237-239. doi:10.1093/icvts/ivt441

11. Gonzalez-Rivas D, Fieira E, de la Torre M, Delgado M. Bronchovascular right upper lobe reconstruction by uniportal video-assisted thoracoscopic surgery. $J$ Thorac Dis. 2014;6:861-863. doi:10.3978/j.issn.2072-1439.2014.06.27

12. Goldstraw P, Chansky K, Crowley J, et al. The IASLC lung cancer staging project: proposals for revision of the TNM Stage Groupings in the Forthcoming (eighth) edition of the TNM classification for lung cancer. J Thoracic Oncol. 2016;11:39-51. doi:10.1016/j.jtho.2015.09.009

13. Jiang $\mathrm{L}$, Wu L, Roque SR, Jiang G. A novel tourniquet technique for transient pulmonary artery occlusion during video-assisted thoracoscopic surgery. J Thorac Cardiovasc Surg. 2018;156:816-818. doi:10.1016/j.jtcvs.2018.02.066

14. Takeda S, Maeda H, Koma M, et al. Comparison of surgical results after pneumonectomy and sleeve lobectomy for non-small cell lung cancer. trends over time and 20-year institutional experience. Eur J CardioThoracic Surg. 2006;29:276-280. doi:10.1016/j.ejcts.2005.12.017

15. Pages PB, Mordant P, Renaud S, et al. Sleeve lobectomy may provide better outcomes than pneumonectomy for non-small cell lung cancer. A decade in a nationwide study. $J$ Thorac Cardiovasc Surg. 2017;153:184-95.e3. doi:10.1016/j.jtcvs.2016.09.060

16. Ludwig C, Stoelben E, Olschewski M, Hasse J. Comparison of morbidity, 30-day mortality, and long-term survival after pneumonectomy and sleeve lobectomy for non-small cell lung carcinoma. Ann Thorac Surg. 2005;79:968-973. doi:10.1016/j.athoracsur. 2004.08.062
17. Long $\mathrm{H}$, Tan $\mathrm{Q}$, Luo Q, et al. Thoracoscopic surgery versus thoracotomy for lung cancer: short-term outcomes of a randomized trial. Ann Thorac Surg. 2018;105:386-392. doi:10.1016/j.athoracsur.2017.08.045

18. Bendixen M, Jorgensen OD, Kronborg C, Andersen C, Licht PB. Postoperative pain and quality of life after lobectomy via video-assisted thoracoscopic surgery or anterolateral thoracotomy for early stage lung cancer: a randomised controlled trial. Lancet Oncol. 2016;17:836-844. doi:10.1016/S1470-2045(16)00173-X

19. Cao C, Zhu ZH, Yan TD, et al. Video-assisted thoracic surgery versus open thoracotomy for non-small-cell lung cancer: a propensity score analysis based on a multi-institutional registry. Eur $J$ CardioThoracic Surg. 2013;44:849-854. doi:10.1093/ejcts/ezt406

20. Ikeda N, Saji H, Hagiwara M, Ohira T, Usuda J, Kajiwara N. Recent advances in video-assisted thoracoscopic surgery for lung cancer. Asian J Endosc Surg. 2013;6:9-13. doi:10.1111/ases.2013.6.issue-1

21. Xue Y, Wang YY, Zhang K, Cong W, He B, Zeng FC. A study of complete video-assisted thoracoscopic surgery lobectomy in treatment of elderly patients with non-small cell lung cancer: curative effect and impact on clinical prognosis. Cell Biochem Biophys. 2015;73:399-404. doi:10.1007/s12013-015-0649-x

22. Zhang LB, Wang B, Wang XY, Zhang L. Influence of video-assisted thoracoscopic lobectomy on immunological functions in non-small cell lung cancer patients. Med Oncol. 2015;32:201. doi:10.1007/ s12032-015-0639-2

23. Liu L, Mei J, Pu Q, Ma L. Thoracoscopic bronchovascular double sleeve lobectomy for non-small-cell lung cancer. Eur $J$ CardioThoracic Surg. 2014;46:493-495. doi:10.1093/ejcts/ezu103

24. Huang J, Qiu Y, Xu X, et al. Video-assisted thoracoscopic double sleeve lobectomy: a lived video in a nationwide academic conference. J Thorac Dis. 2015;7:496-498. doi:10.3978/j.issn.2072-1439.2015.01.39

25. Huang J, Li J, Qiu Y, et al. Thoracoscopic double sleeve lobectomy in 13 patients: a series report from multi-centers. J Thorac Dis. 2015;7:834-842. doi:10.3978/j.issn.2072-1439.2015.04.55

26. Gonzalez-Rivas D, Delgado M, Fieira E, Fernandez R. Double sleeve uniportal video-assisted thoracoscopic lobectomy for non-small cell lung cancer. Ann Cardiothorac Surg. 2014;3:E2.

27. Lyscov A, Obukhova T, Ryabova V, Sekhniaidze D, Zuiev V, Gonzalez-Rivas D. Double-sleeve and carinal resections using the uniportal VATS technique: a single centre experience. $J$ Thorac Dis. 2016;8:S235-41. doi:10.3978/j.issn.2072-1439.2016.02.25

28. Mahtabifard A, Fuller CB, McKenna RJ Jr. Video-assisted thoracic surgery sleeve lobectomy: a case series. Ann Thorac Surg. 2008;85: S729-32. doi:10.1016/j.athoracsur.2007.12.001

29. Xu X, Chen H, Yin W, et al. Thoracoscopic half carina resection and bronchial sleeve resection for central lung cancer. Surg Innov. 2014;21:481-486. doi:10.1177/1553350613509728

30. Yu D, Han Y, Zhou S, et al. Video-assisted thoracic bronchial sleeve lobectomy with bronchoplasty for treatment of lung cancer confined to a single lung lobe: a case series of Chinese patients. $J$ Cardiothorac Surg. 2014;9:67. doi:10.1186/1749-8090-9-67

31. Zhou S, Pei G, Han Y, et al. Sleeve lobectomy by video-assisted thoracic surgery versus thoracotomy for non-small cell lung cancer. $J$ Cardiothorac Surg. 2015;10:116. doi:10.1186/s13019-015-0318-6

32. Sawada S, Komori E, Yamashita M. Evaluation of video-assisted thoracoscopic surgery lobectomy requiring emergency conversion to thoracotomy. Eur J Cardio-Thoracic Surg. 2009;36:487-490. doi:10.1016/j.ejcts.2009.04.004

33. Tuminello S, Schwartz RM, Liu B, et al. Opioid use after open resection or video-assisted thoracoscopic surgery for early-stage lung cancer. JAMA Oncol. 2018;4:1611-1613. doi:10.1001/ jamaoncol.2018.4387

34. McElnay PJ, Molyneux M, Krishnadas R, Batchelor TJ, West D, Casali G. Pain and recovery are comparable after either uniportal or multiport video-assisted thoracoscopic lobectomy: an observation study. Eur J Cardio-Thoracic Surg. 2015;47:912-915. doi:10.1093/ ejcts/ezu324 
35. Chunwei F, Weiji W, Xinguan Z, Qingzen N, Xiangmin J, Qingzhen Z. Evaluations of bronchoplasty and pulmonary artery reconstruction for bronchogenic carcinoma. Eur J Cardio-Thoracic Surg. 2003;23:209-213. doi:10.1016/S1010-7940(02)00743-1
36. Burfeind WR Jr., D'Amico TA, Toloza EM, Wolfe WG, Harpole DH .Low morbidity and mortality for bronchoplastic procedures with and without induction therapy. Ann Thorac Surg.2005;80:418-421. doi:10.1016/j.athoracsur.2005.02.058

\section{Publish your work in this journal}

Cancer Management and Research is an international, peer-reviewed open access journal focusing on cancer research and the optimal use of preventative and integrated treatment interventions to achieve improved outcomes, enhanced survival and quality of life for the cancer patient.
The manuscript management system is completely online and includes a very quick and fair peer-review system, which is all easy to use. Visit http://www.dovepress.com/testimonials.php to read real quotes from published authors. 